4. Lukinsky, V. S., Berezhnoy, V. I., \& Berezhnaya, E. I. (2009). Logistics in examples and tasks: Educ. Manual. Moscow: Finance and Statistics. (in Russian)

5. Kurganov, V. M. (2003). Logistic traffic flows. Educ. Manual. Moscow: Publishing and trading corporation «Dashkov and KO». (in Russian)

6. Transport Logistics. Shared solutions to common challenges. Retrieved from:: https://www.itf-oecd.org/sites/default/files/docs/02logisticse.pdf (accessed 25 august 2019).

7. Albino, Vito \& Petruzzelli, Antonio \& Okogbaa, O. G. (2009). Managing Logistics Flows Through Enterprise Input-Output Models. 2008 IEEE International Conference on Industrial Engineering and Engineering Management, IEEM 2008. pp. 852-856. 10.1109/IEEM.2008.4737990.

8. Hesse, Markus \& Rodrigue, Jean-Paul. (2004). The transport geography of logistics and freight distribution. Journal of Transport Geography. 12. pp. 171-184. 10.1016/j.jtrangeo.2003.12.004.

\title{
CHOOSING THE SHAPE OF A SEASONAL HEAT ACCUMULATOR
}

\section{Anna Moskvitina ${ }^{1}$}

DOI: https://doi.org/10.30525/978-9934-588-11-2_11

The exhaustion of traditional fuel resources and environmental degradation adds relevance to research on renewable and alternative energy and the need to bring environmentally friendly energy sources to the energy balance of Ukraine. A promising direction is the use of heat of solar energy for communal heat supply, which can provide large heat needs even in temperate climates. Basically, methods for using the thermal energy of the sun as a whole are cost-effective, but the proportion of thermal solar energy is quite small. It is possible to significantly increase the efficiency of the use of solar energy in the presence of a seasonal heat accumulator of large thermal capacity. The problem of excess heat in the summer, when the demand for it is reduced, is relevant for existing heat-generating enterprises (CHP). It can also be solved by accumulating these surpluses with their further use in the heating period $[1$, p. $44 ; 2$, p. 58].

To reduce the unit cost of 1 GJ of stored heat, the efficient design of the heat accumulator should have minimal heat loss to the environment. When choosing the shape of the heat accumulator in the plan, you should try to simplify its shape as much as possible. Since the greatest heat loss occurs through the walls, it is desirable that their surface area is the smallest. It is well known that with the same volume, the ball has the smallest surface area. However, it is not rational to build a heat accumulator in the form of a ball in an effort to significantly reduce heat loss, since it is very difficult to calculate and constructively execute a spherical heat accumulator. For real construction, the configuration of a heat accumulator in the form of a cube is best suited, since the outer surface area is the smallest in it, so for further calculations

${ }^{1}$ Kiev National University of Construction and Architecture, Ukraine 
we choose just such a shape. But you need to check how the location of the heat accumulator will affect its shape, in which case it is better to adhere to the cubic shape, and in which it is better to use the shape of a parallelepiped [3, p. 105].

Consider how the shape of a heat accumulator depends on its location:

- Option 1 heat accumulator is located under the house;

- Option 2: The heat accumulator is arbitrarily located in the ground.

To calculate the specific indicators, we take the volume of the heat accumulator 1 $\mathrm{m} 3$. Heat loss through any wall of the heat accumulator is determined by:

$$
Q_{h l, i}=\frac{\lambda}{\delta} \cdot\left(t_{h a}^{a}-t_{s}\right) \cdot F_{i}, W
$$

where, $\lambda$ - the thermal conductivity coefficient of the wall of the heat accumulator, $\mathrm{W} /(\mathrm{m} \cdot \mathrm{K})$

$\delta$ - the wall thickness of the heat accumulator, $\mathrm{m}$;

$t_{\text {ha }}{ }^{a}$ - the average temperature of the heat accumulator during the heating period, is defined as the half-sum of the temperatures of charging $\left(t_{c h}\right)$ and discharging $\left(t_{d c h}\right)$ the heat accumulator:

$$
\mathrm{t}_{\mathrm{ha}}{ }^{\mathrm{a}}=\left(\mathrm{t}_{\mathrm{ch}}+\mathrm{t}_{\mathrm{dch}}\right) / 2=(140+55) / 2=97,5^{\circ} \mathrm{C} \text {. }
$$

$\mathrm{t}_{\mathrm{s}}$ - soil temperature, taken $+8{ }^{0} \mathrm{C}$.

$\mathrm{F}_{\mathrm{i}}$ - the area of the walls of the heat accumulator, $\mathrm{m}^{2}$.

Since the depth of immersion of the heat accumulator in the soil most affects its cost during the installation of a heat accumulator, we need an effective form of a heat accumulator with a lower height.

To do this, we denote the length and width of the heat accumulator $-\mathrm{x}$, and the height $-\mathrm{y}$ (Figure 1). We accept the design of the heat accumulator: mineral wool walls with $\lambda=0.045 \mathrm{~W} /(\mathrm{m} \cdot \mathrm{K})$, and the bottom part made of foam glass with $\lambda=0.065 \mathrm{~W} /(\mathrm{m} \cdot \mathrm{K})$, wall thickness $\delta=1.0 \mathrm{~m}$, to simplify the calculation.

For the 1st option, when the heat accumulator is located under the house, heat loss through the upper part of the heat accumulator during the heating period is taken into account as heat input to the house. Then the balance equation for the heat accumulator is as follows:

$$
\mathrm{Q}_{\mathrm{bal}}=\mathrm{Q}_{\mathrm{h} .1 .}-\mathrm{Q}_{\mathrm{h} . \mathrm{i}} \rightarrow \min .
$$

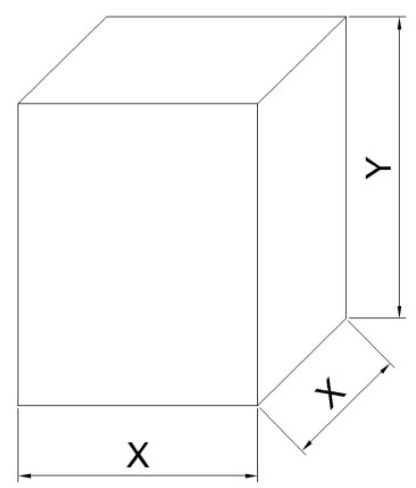

Figure 1. The designation of the sizes of the thermal accumulator for calculations 
Heat loss through the walls and the bottom of the heat accumulator:

$$
\mathrm{Q}_{\mathrm{h} . \mathrm{l}}=(0,065 / 1,0) \cdot(97,5-8) \cdot \mathrm{x}^{2}+(0,045 / 1,0) \cdot 4 \cdot(97,5-8) \cdot \mathrm{x} \cdot \mathrm{y}=5,8175 \cdot \mathrm{x}^{2}+16,11 \cdot \mathrm{x} \cdot \mathrm{y} \text {. }
$$

Heat entering the house through the top of the heat accumulator:

$$
\mathrm{Q}_{\mathrm{h} . \mathrm{i} .}=(0,045 / 1,0) \cdot(97,5-20) \cdot \mathrm{x}^{2}=3,4875 \cdot \mathrm{x}^{2} \text {. }
$$

Heat loss to the environment should be minimal:

$$
\mathrm{Q}_{\text {bal }}=2,33 \mathrm{x}^{2}+16,11 * \mathrm{x} * \mathrm{y} \rightarrow \min \text {. }
$$

The estimated volume is taken $\mathrm{V}=1 \mathrm{~m}^{3}$. Substituting different values of $\mathrm{y}$ and expressing $\mathrm{x}=(1 / \mathrm{y})^{0,5}$, we obtain the value of $\mathrm{Q}_{\mathrm{bal}}$ (table 1).

Table 1

1st option, $Q_{\text {bal }}$ value depending on the height $y$

\begin{tabular}{|c|c|c|}
\hline Height $\mathbf{y}, \mathbf{m}$ & Width and length $\mathbf{x}, \mathbf{m}$ & Heat loss $\mathbf{Q}_{\text {bal }}, \mathbf{W}$ \\
\hline 1 & 1 & 13,171 \\
\hline 0,9 & 1,0541 & 12,766 \\
\hline 0,8 & 1,118 & 12,373 \\
\hline 0,7 & 1,1952 & 12,005 \\
\hline 0,6 & 1,291 & 11,687 \\
\hline 0,5 & 1,4142 & 11,465 \\
\hline 0,4 & 1,5811 & 11,438 \\
\hline 0,3 & 1,8257 & 11,85 \\
\hline 0,2 & 2,2361 & 13,468 \\
\hline 0,1 & 3,1623 & 20,282 \\
\hline
\end{tabular}

That is, for the option of placing a heat accumulator under the house, the effective form of the heat accumulator is a parallelepiped with a height $\mathrm{y}=0.4 \mathrm{~m}$, width and length $\mathrm{x}=1.58 \mathrm{~m}$, but the width and length of the heat accumulator should not go beyond the dimensions of the building in plan.

For the 2nd option, when placing a heat accumulator arbitrarily in the ground, the heat balance equation has the form:

$$
\mathrm{Q}_{\text {bal }}=\mathrm{Q}_{\text {h.l.. }} \rightarrow \min .
$$

Heat loss through the walls of the heat accumulator:

$$
\begin{aligned}
\mathrm{Q}_{\mathrm{bal}} & =\mathrm{Q}_{\mathrm{h} .1}=(0,065 / 1,0) \cdot(97,5-8) \cdot \mathrm{x}^{2}+(0,045 / 1,0) \cdot 4 \cdot(97,5-8) \cdot \mathrm{x} \cdot \mathrm{y}+ \\
& +(0,045 / 1,0) \cdot(97,5-20) \cdot \mathrm{x}^{2}=9,305 \mathrm{x}^{2}+16,11 \cdot \mathrm{x} \cdot \mathrm{y} . \rightarrow \mathrm{min} .
\end{aligned}
$$

Substituting different values of $y$ and expressing $x=(1 / y)^{0,5}$, we obtain the value of Qbal (table 2).

That is, for the option of placing the heat accumulator arbitrarily in the ground, the effective form of the heat accumulator is a cube. 
2nd option, $Q_{\text {bal }}$ value depending on the height $y$

\begin{tabular}{|c|c|c|}
\hline Height $\mathbf{y}, \mathbf{m}$ & Width and length $\mathbf{x}, \mathbf{m}$ & Heat loss $\mathbf{Q}_{\text {bal }}, \mathbf{W}$ \\
\hline 1 & 1 & 18,154 \\
\hline 0,9 & 1,0541 & 18,302 \\
\hline 0,8 & 1,118 & 18,6 \\
\hline 0,7 & 1,1952 & 19,122 \\
\hline 0,6 & 1,291 & 19,991 \\
\hline 0,5 & 1,4142 & 21,43 \\
\hline 0,4 & 1,5811 & 23,894 \\
\hline 0,3 & 1,8257 & 28,457 \\
\hline 0,2 & 2,2361 & 38,378 \\
\hline 0,1 & 3,1623 & 70,103 \\
\hline
\end{tabular}

\section{References:}

1. Beckman, N.G., Gilli, P. (1987). Thermal energy storage. Moscow: World.

2. Duffy, J. A., Beckman, W. A. (1977). Thermal processes using solar energy. Moscow: World.

3. Anderson B. Solar Energy (1982). Fundamentals of building design. Moscow: Stroiizdat.

\section{APPEARANCE OF TURBIDITY IN ALCOHOLIC BEVERAGES}

\section{Oleksandr Ostryk ${ }^{1}$ \\ Svitlana Oliynyk ${ }^{2}$}

DOI: https://doi.org/10.30525/978-9934-588-11-2_12

Transparency of alcohols is one of the main components of their presentation. Thus predicting the resistance to different types of turbidity is their important quality indicator.

Alcoholic beverages should meet the requirements of the national standards according to organoleptic, physico-chemical parameters and the expiration date, which is established after determining the projected resistance. The expiration date of alcoholic beverages should not exceed their predicted resistance. In this regard, manufacturers are demanding heigh quality and following technological modes of processing raw materials, semi-finished products and beverages in order to achieve their guaranteed stability.

However, while storing the alcoholic beverages may not last the expiration dates, they attain turbidity, color changes, sediments. Turbidity is produced in alcoholic

\footnotetext{
${ }^{1}$ National University of Food Technology, Ukraine

${ }^{2}$ National University of Food Technology, Ukraine
} 